\title{
Urgences
}

\section{Dominique Noguez, Les trois Rimbaud, Paris, Minuit, 1986, 62}

p.

\section{André Gervais}

Numéro 15, octobre 1986

Épigraphiques

URI : https://id.erudit.org/iderudit/025364ar

DOI : https://doi.org/10.7202/025364ar

Aller au sommaire du numéro

\section{Éditeur(s)}

Urgences

\section{ISSN}

0226-9554 (imprimé)

1927-3924 (numérique)

Découvrir la revue

Citer ce compte rendu

Gervais, A. (1986). Compte rendu de [Dominique Noguez, Les trois Rimbaud, Paris, Minuit, 1986, 62 p.] Urgences, (15), 115-116.

https://doi.org/10.7202/025364ar d'utilisation que vous pouvez consulter en ligne.

https://apropos.erudit.org/fr/usagers/politique-dutilisation/ 
nous incite à vouloir lire les poètes danois. Heureusement qu'il existe en français, et cela depuis 1975, une excellente Anthologie de la poésle danoise contemporaine publiée chez Gallimard sous les soins de Jorgen Gustava Brandt, Uffe Harder et Klaus Rifbjerg. Vous pourrez $y$ lire des poètes teis que Sophus Claussen (1865-1931), poète préféré de Karen Blixen, ou encore Thorkild Bjomvig (1918- ) son ami de coeur et protégé. Enfin, en plus de mieux connaître cette auteure, vous allez avoir le goat de lire toute son oeuvre...

Guy Rancourt

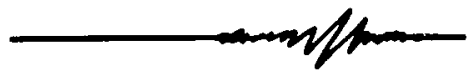

\section{Dominique Noguez: Les trois Rimbaud, $\mathrm{Pa}$ - ris, Minuit, 1986, 62 p.}

Qui ne connaît pas ce cher Arthur, qui écrivit (toute! toute?) son oeuvre de 1869 à $1875-1876$, de 15 ans à $21-22$ ans. Ou son "cousin" d'outreAtlantique Emile, qui écrivit (id.! id.?) son oeuvre de 1896 à 1899 , de 16 à 19 ans.

Qui ne connaît pas "La chasse spirituelle", cette fausse prose à lui attribuée, une affaire qui défraya la chronique parisienne en 1949. Voir, là-dessus, le pamphlet d'André Breton: "Flagrant délit" (dans La clé des champs, coll. "10/18", 750, [1953], p. 209-273).

Qui ne connaît pas, enfin, "la plaisante fiction d'Alain Borer qui, dans son Rimbaud en Abyssinie (en note: $\mathrm{Pa}$ ru en 1984 aux Éditions du Seuil, dans la collection, bien nommée, Fiction \& Cie...], prête à l'écrivain le destin de son personnage des Nuits d'Afrique, le fait donc mourir vers 1891 des suites d'une amputation de la jambe, et s'amuse ensuite à imaginer l'idée que nous nous ferions aujourd' hui de lui si, à Dieu ne plût, tel avec été le cas (petit jeu littéraire qui ne manque pas d'intérêt et qui vaudrait d'être pratiqué sur d'autres: comment verrions-nous Gide s'il était mort après Les Nourritures terrestres, Aragon après le Traité du style ou Joyce après The Dubll. ners?...)" (p. 27).

Il aura donc fallu attendre Dominique Noguez pour indiquer la "voie comparative" (p. 62) nécessaire à la relecture de l'oeuvre une, certes, mais selon les deux majeures coupures qu'il est désormais convenu d'envisager, "pour ce qui est de la vie" (p. 13):

- le premier Rimbaud, "trop souvent oublié" (p. 30): de sa naissance (1854) à 1875; celui des premières fugues et des oeuvres d'adolescence: Poesies, Vers nouveaux et chansons (fin 1871-1872), Une saison en enfer (1873), Illuminations;

- le deuxième Rimbaud: de 18751876 à 1891: celui du "silence" littéraire, des longs voyages en Europe, un peu en Orient et, surtout, des longues explorations en Afrique, jusqu' au retour incognito à Paris;

- le troisième Rimbaud: de 18911893 à sa mort (1937): celui des "rechutes" - les guillemets sont de D.N. (p. 24) - presque officielles (en Chine, aux États-Unis) et des oeuvres importantes et bien connues de la maturité et de la vieillesse: Les Nuits d'Afrique (1893), Système de la vie moderne (1899-1911, inachevé), L (1910), L'É. vangile noir (1928) et Regards sans yeux (1934).

L'intérêt de cette brève étude, illustrée de quelques documents, est bien de replacer les grandes oeuvres bien connues, trop (mal) connues - n'ontelles pas mené leur auteur à l'Académie française (1930), où il est reçu par Valéry -, dans la contradictoire continuité d'Une saison en enfer, surtout, "texte décidément capital"' (p. 58):

En somme, le urai lieu de Rimbaud est la racine brülante de la contradic- 
tion, le moment intenable où l'on passe du oul au non, du blanc au noir. $\mathrm{Ce}$ moment que les penseurs, d'ordinaire, dépassent et oublient, Rimbaud y revient, obstinément, s'y vautre, comme par une malédiction consentie. (p. 56)

Simplement, ce qui en 1873 est condensé dans les quelques pages d'un même texte se développe ensuite, s'orchestre, d'un texte majeur à l'autre. Avec, certes, notamment après la conversion [1925], des accalmies plus longues, le triomphe relatif de la "gráce" sur le "sang païen", mais - toujours la "dialectique avortée"! - sans qu'on parvienne davantage à une ressolution vraiment définitive. (p. 60)

S'y vautre, s'orchestre: dans cette rime où s'assemblent la désignation plutôt insistante d'un lieu et le développement en quelque sorte continu d'une inscription (a partir de ce lieu), se trouve ce titre (etre les trois Rimbaud) par lequel veut bien être rappelé que de chaque côté d'un (et du) silence il y a, à l'étroit, de la parole, c'est-à-dire de l'écriture.

Étude fine et décapante, on le dirait à moins, menée dans l'intratexte généralisé selon ladite "voie comparative", et qui falt appel à (et rappel d') une panoplie d'autres textes et de "noms": lettres $\mathrm{a}$, joumaux intimes et conferences de, par exemple, J.-K. Huysmans, F. Pessoa, R. Gilbert-Lecomte, P. Léautaud, A. Gide, P. Claudel, L. Blum et Th. Mann.

Étude ratoureuse à souhait, bien dans le droit fil du tout jeune Rimbaud qui "aide" - selon l'un des sens que Marcel Duchamp donne à "ready-made aidé": rectifié littérairement, corrigé - telle traduction donnée (en mai 1869) par Sully-Prudhomme du De natura rerum de Lucrèce, la signe de son nom et la publie dans le Bulletin de I'Académie de Doual (fascicule du 11 avril 1870). Dans le droit fil, egalement, de telle "Sémiologie du parapluie" que le même Dominique Noguez publia dans un no intitule Vers une esthetique sans entrave de la Revue d'esthétlque (coll. "10/18", 931, 1975, p. 387398) en guise d'hommage au philosophe et esthéticien Mikel Dufrenne. Voyez-vous l'affaire!

André Gervals 